\title{
Chiral and achiral helical coordination polymers of zinc and cadmium from achiral 2,6-bis(imidazol-1-yl)pyridine: Solvent effect and spontaneous resolution
}

\author{
SARITA TRIPATHI, RENGANATHAN SRIRAMBALAJI, NAMITA SINGH and \\ GANAPATHI ANANTHARAMAN* \\ Department of Chemistry, Indian Institute of Technology, Kanpur 208 016, India \\ e-mail: garaman@iitk.ac.in
}

MS received 13 February 2014; revised 5 April 2014; accepted 7 April 2014

\begin{abstract}
Four 2D helical coordination polymers (CPs) (1-4) were synthesized using achiral 2,6-bis (imidazol-1-yl)pyridine $\left(\right.$ pyim $\left._{2}\right)$ ligand with metal nitrates (metal = zinc and cadmium), which showed that variation in the solvent condition leads to difference in geometry around the central metal ion and results in chiral/achiral behaviour of these CPs. By using $($ pyim 2$),\left[\text { trans- } \mathrm{Zn}\left(\mathrm{pyim}_{2}\right)_{2}\left(\mathrm{NO}_{3}\right)_{2}\right]_{\mathrm{n}}$ (1) was obtained by unary solvent $(\mathrm{MeOH})$, while $\left.[\text { trans-Cd(pyim })_{2}\left(\mathrm{NO}_{3}\right)_{2}\right]_{n}(\mathbf{2})$ was formed under binary solvent mixtures $(\mathrm{DMF} / \mathrm{MeOH})$. On the other hand, in ternary solvent mixture $\left(\mathrm{DMF} / \mathrm{MeOH} / \mathrm{H}_{2} \mathrm{O}\right)$ it resulted into an achiral $\left.\left\{\left[\text { trans- } \mathrm{Zn}(\text { pyim })_{2}\right)_{2}\left(\mathrm{H}_{2} \mathrm{O}\right)_{2}\right] \cdot\left(\mathrm{NO}_{3}\right)_{2}\right\}_{\mathrm{n}}(3)$ and homochiral $\left\{\left[\text { cis- } \mathrm{Cd}\left(\text { pyim }_{2}\right)_{2}\left(\mathrm{H}_{2} \mathrm{O}\right)_{2}\right] \cdot\left(\mathrm{NO}_{3}\right)_{2}\right\}_{\mathrm{n}}(\mathbf{4})$ coordination polymer, respectively. The homochiral behaviour of the coordination polymer (4) was further studied by solid state CD spectra and also its optical behaviour was analyzed by polarimetry.
\end{abstract}

Keywords. Chirality; helical structures; spontaneous resolution; coordination polymers-cadmium; zinc

\section{Introduction}

Coordination polymers (CPs) have been an area of profound interest over the past two decades, not only for their rational design and intriguing topologies, but also for their potential application in various fields like storage, separation, magnetism, catalysis, and non-linear optics. ${ }^{1-5}$ Among the reported CPs, in recent years, a significant research interest has been devoted for chiral helical structural motifs. ${ }^{6}$ Chirality is one of the most important aspects of nature and is an intrinsic feature of various states of matters. Chirality and helicity are closely related terms and are strongly associated with the biological systems; in particular, chirality is often expressed as helical motifs in nature. Moreover, these helical architectures not only have fascinating structural features, but they have been playing several key functions in natural systems. ${ }^{7}$

Emulating nature's design in artificial systems like chiral helical CPs is an interesting area of research. Generally, there are four different strategies to prepare homochiral CPs. ${ }^{8}$ First, by the use of readily available chiral ligands, which serve as the building blocks and thus, transfer their chiral behavior to the resulting CP. ${ }^{9}$ Second, the use of chiral auxiliary ligands, which bind

\footnotetext{
*For correspondence
}

to the metal ion and induce homochirality in the $\mathrm{CP}$ formed. ${ }^{10}$ Third, by using chiral templates, solvents or additives which may induce chirality in the resultant framework. ${ }^{11}$ Finally, by simply using achiral ligands and metal precursors, in which spontaneous resolution occurs due to the chiral spatial arrangement of ligands coordination around the metal ion. ${ }^{12-15}$ The advantage provided by the last method lies in the fact that it does not use any chiral components, which are difficult to prepare and some of them are quite expensive.

In general, the synthesis of chiral helical CPs using semi-rigid/flexible achiral ligands is a challenging research field. Many of the structures reported in the literature are either racemic, with both $P(\Delta)$ and $M(\Lambda)$ helices running along the crystallographic axis, or conglomerates, wherein both $P$ and $M$ crystals are present in the reaction mixture and the structure remains unpredictable. $^{8}$

In contrast, the preparation of chiral coordination complexes is a very well established procedure and it dates back to Werner, who showed that the complex chirality depends on formation of cis coordination geometry around the metal ion with appropriate chelating/ monodentate ligands. This can be understood based on the symmetry criteria that the absence of improper axis of rotation results in chirality. ${ }^{16}$ Keeping this in view, if one analyzes the coordination geometry of the 
metal centers in the reported structures of helical CPs, it can be seen that the racemic structures are present in cases where the metal coordination geometry is trans, whereas, homochiral CPs are found to have cis coordination geometry at the metal centers with at least one chelating or two heteroatomic mono-dentate ligands. ${ }^{12-15}$

Considering these facts, we have chosen an angular semi-rigid achiral ligand, of 2,6-bis(imidazol-1-yl)pyridine $\left(\text { pyim }_{2}\right)^{17}$ and carried out the reactions with zinc and cadmium nitrates under different solvent mixtures. In this paper, we report the synthesis of four CPs, [trans$\left.\mathrm{M}\left(\text { pyim }_{2}\right)_{2}\left(\mathrm{NO}_{3}\right)_{2}\right]_{\mathrm{n}} \quad[\mathrm{M}=\mathrm{Zn}(\mathbf{1}), \mathrm{Cd}(\mathbf{2})], \quad\{[$ trans$\left.\mathrm{Zn}\left(\text { pyim }_{2}\right)_{2}\left(\mathrm{H}_{2} \mathrm{O}\right)_{2}\right] \cdot\left(\mathrm{NO}_{3}\right)_{2}(\mathbf{3})$ and $\left\{\left[\right.\right.$ cis-Cd $\left(\text { pyim }_{2}\right)_{2}$ $\left.\left.\left(\mathrm{H}_{2} \mathrm{O}\right)_{2}\right] \cdot\left(\mathrm{NO}_{3}\right)_{2}\right\}_{\mathrm{n}}$ (4), (scheme 1). Among these CPs, 1-3 are achiral, whereas 4 crystallize in chiral space group $C 2$. Also the solubility of $\mathbf{4}$ in DMSO helped in evaluation of its solution behaviour using NMR and polarimetry.

Previously, Lee and co-workers studied the conformational effects of pyim $_{2}$ in the preparation of zinc halide CPs under hydrothermal or solvothermal conditions. ${ }^{17 a}$ Interestingly, the hydrothermal reactions resulted in the formation of conglomerates, with larger $\mathrm{N} \cdots \mathrm{N} \cdots \mathrm{N}$ angle $\left(161^{\circ}\right)$, whereas, zig-zag and single helical structures, with shorter $\mathrm{N} \cdots \mathrm{N} \cdots \mathrm{N}$ angle $\left(142^{\circ}\right.$ and $\left.122^{\circ}\right)$, were formed respectively under the solvothermal reaction. In general, the hydrothermal or solvothermal reactions yield only the most stable products. However to understand structural transformations, milder experimental conditions are necessary.

\section{Experimental}

\subsection{Materials and general procedures}

$\mathrm{Zn}\left(\mathrm{NO}_{3}\right)_{2} \cdot 6 \mathrm{H}_{2} \mathrm{O}$ and $\mathrm{Cd}\left(\mathrm{NO}_{3}\right)_{2} \cdot 4 \mathrm{H}_{2} \mathrm{O}$ were obtained from SD fine Chemicals, India. All chemicals were used without further purification. Solvents were first dried and then used after distillation. Elemental analyses were performed with an EAI Exeter analytical, INC
CE-440 Elemental analyzer. IR spectra were recorded by using $\mathrm{KBr}$ pellets in the region $400-4000 \mathrm{~cm}^{-1}$ on Bruker model vertex 70. Thermogravimetric analyses were done in $\mathrm{N}_{2}$ atmosphere with a heating rate of $10^{\circ} \mathrm{C} / \mathrm{min}$ on Mettler Toledo Star System. NMR was recorded on JEOL ECX-500. The CD spectrum was recorded on Jasco J-815 spectropolarimeter. The polarimetry was recorded on Rudolph Research analytical Autopol II Automatic Polarimeter. Powder X-ray diffraction (PXRD) data were collected on a PANalytical X'Pert Pro X-ray diffractometer with radiation $\mathrm{Cu}$ $\mathrm{K} \alpha$ radiation $(\lambda=1.540598 \AA$ ) at room temperature with a scan step size of 0.02 in $2 \theta$. DIAMOND (version 3.0) and Mercury (version 2.4) were used to view and draw the structures.

\subsection{Preparation of 2,6-bis(imidazol-1-yl)pyridine $\left(\right.$ pyim $\left._{2}\right)$}

The ligand, pyim $_{2}$ was prepared according to the literature procedure. ${ }^{17 \mathrm{~b}}{ }^{1} \mathrm{H}-\mathrm{NMR}\left(\mathrm{DMSO}-d_{6}, 500 \mathrm{MHz}, \delta\right.$ ): $7.11(s, 2 \mathrm{H}, \mathrm{H} 4-\mathrm{Im}), 7.70(d, J=5 \mathrm{~Hz}, 2 \mathrm{H}, \mathrm{H} 3-\mathrm{Py})$, $8.08(s, 2 \mathrm{H}, \mathrm{H} 5-\mathrm{Im}), 8.13$ ( $t, J=10 \mathrm{~Hz}, 1 \mathrm{H}, \mathrm{H} 4-\mathrm{Py})$, $8.70(s, 2 \mathrm{H}, \mathrm{H} 2-\mathrm{Im})$.

\subsection{Synthesis of CPs 1-4}

2.3a Synthesis of [trans- $\left.\mathrm{Zn}\left(\text { pyim }_{2}\right)_{2}\left(\mathrm{NO}_{3}\right)_{2}\right]_{n}(1)$ : To a solution of $\mathrm{Zn}\left(\mathrm{NO}_{3}\right)_{2} \cdot 6 \mathrm{H}_{2} \mathrm{O}(0.074 \mathrm{~g}, 0.25 \mathrm{mmol})$ in methanol $(40 \mathrm{~mL})$, pyim $_{2}(0.106,0.5 \mathrm{mmol})$ was added as solid and the solution was stirred for $30 \mathrm{~min}$. The solution was allowed to evaporate at room temperature very slowly to afford colourless crystals after few weeks. Yield: $0.055 \mathrm{~g}, 36 \%$ based on $\mathrm{Zn}\left(\mathrm{NO}_{3}\right)_{2} \cdot 6 \mathrm{H}_{2} \mathrm{O}$. Anal. calcd. for $\mathrm{C}_{22} \mathrm{H}_{18} \mathrm{~N}_{12} \mathrm{O}_{6} \mathrm{Zn}$ (611.85): C, 43.19; H, 2.96; N, 27.47. Found: C, 42.50; H, 2.73; N, 28.00. IR $\left(\mathrm{KBr}, \mathrm{cm}^{-1}\right.$ ): 3182 (s), 3168 (s), 3136 (vs), 3119 (vs), 1606 (vs), 1585 (vs), 1502 (vs), 1462 (vs), 1420 (vs), 1309 (vs), 1254 (vs), 1238 (s), 1178 (s), 1139 (vs), 1120 (vs), 1073 (s), 1039 (s), 1007 (s), 837 (s), 805 (s), 777 (s), $763(\mathrm{~s}), 675(\mathrm{~s}), 658(\mathrm{~m}), 532(\mathrm{w})$.

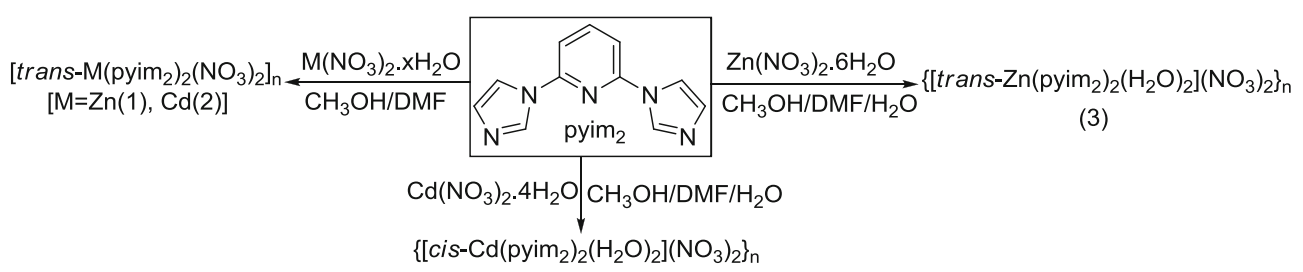

(4)

Scheme 1. Synthesis of CPs 1-4 
$2.3 \mathrm{~b}$ Synthesis of [trans-Cd(pyim $\left.)_{2}\left(\mathrm{NO}_{3}\right)_{2}\right]_{n}(2)$ : Pyim $_{2}(0.053,0.25 \mathrm{mmol})$ in methanol $(2 \mathrm{~mL})$ was layered over a solution of $\mathrm{Cd}\left(\mathrm{NO}_{3}\right)_{2} \cdot 4 \mathrm{H}_{2} \mathrm{O}(0.039 \mathrm{~g}$, $0.125 \mathrm{mmol})$ in DMF $(1 \mathrm{~mL})$. The solution was allowed to stand at room temperature to afford colourless crystals. The same product was obtained, if this reaction was carried out only in methanol. Yield: $62 \%$ based on $\mathrm{Cd}\left(\mathrm{NO}_{3}\right)_{2} \cdot 4 \mathrm{H}_{2} \mathrm{O}$. Anal. Calcd. for $\mathrm{C}_{22} \mathrm{H}_{18} \mathrm{~N}_{12} \mathrm{O}_{6} \mathrm{Cd}$ (658.88): C, 40.10; H, 2.75; N, 25.51. Found: C, 39.49; $\mathrm{H}, 2.27$; N, 25.03. IR $\left(\mathrm{KBr}, \mathrm{cm}^{-1}\right): 3159$ (w), 2923 (w), 2853 (w), 1606 (s), 1585 (s), 1498 (vs), 1463 (vs), 1422 (s), 1310 (vs), 1250 (vs), 1236 (m), 1178 (m), 1139 (m), $1115(\mathrm{~m}), 1070(\mathrm{~s}), 1039(\mathrm{~s}), 1007(\mathrm{~s}), 992(\mathrm{~m})$, $964(\mathrm{~m}), 929(\mathrm{~m}), 882(\mathrm{~m}), 833(\mathrm{~m}), 807(\mathrm{~m}), 777(\mathrm{~m})$, $764(\mathrm{~m}), 753(\mathrm{~m}), 674(\mathrm{~m}), 655(\mathrm{~m}), 621(\mathrm{~m}), 533(\mathrm{w})$, $469(\mathrm{w})$.

2.3c Synthesis of $\left\{\left[\text { trans- } \mathrm{Zn}\left(\text { pyim }_{2}\right)_{2}\left(\mathrm{H}_{2} \mathrm{O}\right)_{2}\right] \cdot\left(\mathrm{NO}_{3}\right)_{2}\right\}_{n}$ (3): To a solution of $\mathrm{Zn}\left(\mathrm{NO}_{3}\right)_{2} \cdot 6 \mathrm{H}_{2} \mathrm{O} \quad(0.074 \mathrm{~g}$, $0.25 \mathrm{mmol})$ in DMF (4 mL), a solution of pyim 2 $(0.106 \mathrm{~g}, 0.5 \mathrm{mmol})$ in methanol $(8 \mathrm{~mL})$ was layered. Further, distilled $\mathrm{H}_{2} \mathrm{O}(25 \mathrm{~mL})$ was layered over the top of this solution. The solution was allowed to stand at room temperature to afford colourless crystals in two days. Yield $0.11 \mathrm{~g}, 34 \%$ based on $\mathrm{Zn}\left(\mathrm{NO}_{3}\right)_{2} \cdot 6 \mathrm{H}_{2} \mathrm{O}$. Anal. calcd. for $\mathrm{C}_{22} \mathrm{H}_{22} \mathrm{~N}_{12} \mathrm{O}_{8} \mathrm{Zn}$ (647.89): C, 40.78; H, 3.42; N, 25.94. Found: C, 40.92; H, 3.33; N, 25.58. IR $\left(\mathrm{KBr}, \mathrm{cm}^{-1}\right.$ ): 3387 (br), 3260 (br), 3128 (s), 1729 (w), 1672 (w), 1606 (vs), 1589 (m), 1493 (vs), 1462 (vs), 1388 (vs), 1348 (vs), 1289 (vs), 1253 (s), 1242 (vs), $1180(\mathrm{~m}), 1137(\mathrm{w}), 1110(\mathrm{~m}), 1081(\mathrm{~m}), 1070(\mathrm{~s}), 1006$ (m), 993 (w), 963 (w), 930 (m), 868 (m), 826 (w), 802 (s), $759(\mathrm{~s}), 677(\mathrm{~s}), 659(\mathrm{w}), 620(\mathrm{w}), 537(\mathrm{br}){ }^{1} \mathrm{H}-\mathrm{NMR}$ (DMSO- $d_{6}, 500 \mathrm{MHz}, \delta$ ): $7.12(s, 2 \mathrm{H}, \mathrm{H} 4-\mathrm{Im}), 7.72(d$, $J=10 \mathrm{~Hz}, 2 \mathrm{H}, \mathrm{H} 3-\mathrm{Py}), 8.10(s, 2 \mathrm{H}, \mathrm{H} 5-\mathrm{Im}), 8.14(t, J$ $=25 \mathrm{~Hz}, 1 \mathrm{H}, \mathrm{H} 4-\mathrm{Py}), 8.72$ ( $s, 2 \mathrm{H}, \mathrm{H} 2-\mathrm{Im})$.

2.3d Synthesis of $\left.\left\{[\text { cis-Cd(pyim })_{2}\left(\mathrm{H}_{2} \mathrm{O}\right)_{2}\right] \cdot\left(\mathrm{NO}_{3}\right)_{2}\right\}_{n}$ (4): Similar procedure as that of 3 except that $\mathrm{Cd}\left(\mathrm{NO}_{3}\right)_{2} \cdot 4 \mathrm{H}_{2} \mathrm{O}(0.078 \mathrm{~g}, 0.25 \mathrm{mmol})$ was used in place of $\mathrm{Zn}\left(\mathrm{NO}_{3}\right)_{2} \cdot 6 \mathrm{H}_{2} \mathrm{O}$. The solution was allowed to stand at room temperature to afford white crystals within a day. Yield, $0.24 \mathrm{~g}, 71 \%$ based on $\mathrm{Cd}\left(\mathrm{NO}_{3}\right)_{2}$. $4 \mathrm{H}_{2} \mathrm{O}$. Anal. calcd. for $\mathrm{C}_{22} \mathrm{H}_{22} \mathrm{~N}_{12} \mathrm{O}_{8} \mathrm{Cd}$ (694.92): $\mathrm{C}$, 38.03; H, 3.19; N, 24.19 Found: C, 38.46; H,3.02; N, 23.85. IR (KBr, cm $\left.{ }^{-1}\right): 3392$ (br), 3263 (br), 3157 (w), 3124 (m), 1673 (w), 1605 (vs), 1589 (m), 1489 (vs), 1462 (vs), 1389 (s), 1345 (vs), 1289 (s), 1253 (s), 1242 (vs), 1180 (m), 1137 (w), 1111 (m), 1068 (s), 1005 (w), $963(\mathrm{w}), 927(\mathrm{w}), 867(\mathrm{w}), 827(\mathrm{~m}), 802(\mathrm{w}), 757$ (w), 677 (m), $656(\mathrm{w}), 619$ (w), 535 (br). ${ }^{1} \mathrm{H}-\mathrm{NMR}$ (DMSO- $d_{6}, 500 \mathrm{MHz}, \delta$ ): 7.13 ( $\left.s, 2 \mathrm{H}, \mathrm{H} 4-\mathrm{Im}\right), 7.73(d$,
$J=10 \mathrm{~Hz}, 2 \mathrm{H}, \mathrm{H} 3-\mathrm{Py}), 8.11(s, 2 \mathrm{H}, \mathrm{H} 5-\mathrm{Im}), 8.14(t$, $J=20 \mathrm{~Hz}, 1 \mathrm{H}, \mathrm{H} 4-\mathrm{Py}), 8.72$ ( $s, 2 \mathrm{H}, \mathrm{H} 2-\mathrm{Im})$.

\section{$2.4 X$ - ray crystallography}

The single crystal X-ray data were collected on Bruker Smart Apex diffractometer using graphite monochromated Mo K $\alpha$ radiation $(\lambda=0.71073 \AA)$. All the structures were solved using SHELXS-97 and refined by full-matrix least squares on $F^{2}$ using SHELXL-97. All hydrogen atoms were included in idealized positions using a riding model. Non-hydrogen atoms were refined with anisotropic displacement parameters. ${ }^{20-22}$

\section{Results and Discussion}

\subsection{Synthesis}

The room temperature syntheses of all the CPs were carried out by taking the metal nitrates of zinc and cadmium with pyim $_{2}$ in the stoichiometric ratio 1:2. By using a unary solvent $(\mathrm{MeOH})$ and binary solvent systems (MeOH/DMF), the CPs $\mathbf{1}$ and $\mathbf{2}$ were obtained respectively. These polymers were insoluble in common organic solvents. The formulations were confirmed by the elemental analyses and it is in very good agreement with the single crystal X-ray crystallographic studies.

It has been established that the use of solvents in the reaction medium play a critical role in the formation of CPs. ${ }^{17}$ In particular, water assisted structural changes have been studied recently by Zhang and co-workers. ${ }^{18}$ Also, earlier, Aoyoma and others had shown that the solvent assisted formation of stereoisomeric products resulted in the formation of chiral CPs, in some cases. ${ }^{15}$ In order to ascertain the possibility of the formation of stereoisomeric product, the reactions of metal nitrates of zinc and cadmium with pyim ${ }_{2}$ were carried out in 1:2 molar ratios using the ternary solvent system $\left(\mathrm{MeOH} / \mathrm{DMF} / \mathrm{H}_{2} \mathrm{O}\right)$. Indeed the products obtained (3 and 4) were different, from 1 and $\mathbf{2}$ irrespective of the similar composition of the starting materials. Both the compounds (3 and $\mathbf{4}$ ) were insoluble in common organic solvents except in DMSO, in which they show moderate solubility. The ${ }^{1} \mathrm{H}$ NMR spectra of $\mathbf{3}$ and $\mathbf{4}$ recorded in DMSO- $d_{6}$ did not have any appreciable change from the ligand spectrum. The IR spectra indicated a broad absorption peak around $3400 \mathrm{~cm}^{-1}$ suggesting the presence of water molecules in $\mathbf{3}$ and $\mathbf{4}$. The final structure were confirmed unambiguously by the single crystal X-ray structural analysis. 


\subsection{Crystal structures}

The single crystal X-ray structure analysis reveals that both the polymeric structures $\mathbf{1}$ and $\mathbf{2}$ crystallize in monoclinic space group $P 2_{1} / n$ and they are isostructural (table 1). The important bond distances and angles are given in legend of figure 1 . The zinc and cadmium ions are in octahedral trans coordination geometry of $\mathrm{MN}_{4} \mathrm{O}_{2}$ environment with ligation from four nitrogen atoms of different imidazole units of pyim ${ }_{2}$ in the plane and two oxygen atoms of two different nitrate ions bound to the metal from its axial position (figure 1a). The other imidazole ring of pyim $_{2}$ connects the metal ions by the planes of the octahedron to form the 2D rhombic grid structures (figure $1 \mathrm{~b}$ ). Within the $2 \mathrm{D}$ network of $\mathbf{1}$ and $\mathbf{2}$, all the 1D chains run into two nearly perpendicular directions and no interpenetration between the chains were observed.

The average $\mathrm{Zn}-\mathrm{N}$ and the $\mathrm{Cd}-\mathrm{N}$ bond distances are 2.135(3) $\AA$ and 2.327(3) $\AA$ respectively (figure 1). The $\mathrm{Zn}-\mathrm{O}$ and the $\mathrm{Cd}-\mathrm{O}$ bond distances are 2.201(3) $\AA$ and 2.344(4) $\AA$ respectively and are consistent with those of reported values [M(2,5-bis(4'-(imidazol-1yl)benzyl)-3,4-diaza-2,4-hexadiene $\left.)_{2}\left(\mathrm{NO}_{3}\right)_{2}\right]_{\mathrm{n}}[\mathrm{M}=\mathrm{Zn}$, $\mathrm{Cd}] .{ }^{19}$ However, in these structures one of the imidazole ring deviated from the plane of the pyridine ring with a dihedral angle of $37.527(13)^{\circ}$ and $33.376(13)^{\circ}$ (figure S4). Consequently, the individual chains are arranged into a helical mode, with different chirality, left-handed $M(\Lambda)$ and right-handed $P(\Delta)$, to form a racemic structure (figure $1 \mathrm{c}$ ). The $2 \mathrm{D}$ network of 1 and 2 was further connected by $\mathrm{C}-\mathrm{H} \cdots \mathrm{O}$ interactions arising from the $\mathrm{C}-\mathrm{H}$ of the pyridine ring and oxygen of nitrate ion from the adjacent layer and packed to complete the 3D structure (figure 1d-e).

Single crystal $\mathrm{X}$-ray diffraction study reveals that the complex $\left\{\left[\text { trans- } \mathrm{Zn}\left(\text { pyim }_{2}\right)_{2}\left(\mathrm{H}_{2} \mathrm{O}\right)_{2}\right] \cdot\left(\mathrm{NO}_{3}\right)_{2}\right\}_{\mathrm{n}}(3)$ crystallize in monoclinic space group $P 2_{1} / c$ (table 1 ). Similar to $\mathbf{1}$, the structure of $\mathbf{3}$ is a $2 \mathrm{D}$ helical rhombic grid structure with some marked differences. It consists of a $\mathrm{ZnN}_{4} \mathrm{O}_{2}$ octahedral unit, where zinc is coordinated by four different nitrogen atoms of imidazole ring of pyim $_{2}$ ligand, which are trans to each other in the plane. Whereas, unlike in $\mathbf{1}$, the axial positions of the metal centres are occupied by water molecules, instead of nitrate ions, and they are also trans to each other (figure 2a). The adjacent layers of zinc octahedral units are oriented perpendicular to each other and they are connected through the planes by nitrogen atoms of imidazole rings of pyim 2 to form the $2 \mathrm{D}$ structure (figure 2b). Like 1, here every non-interpenetrating 1D chain has opposite helicity and thus results in the formation of a racemic structure (figure $2 \mathrm{c}$ ). $\mathrm{Zn}-\mathrm{N}$ bond distances in $\mathbf{3}$ are shorter as compared to $\mathbf{1}$ and they are

Table 1. Crystallographic data and structural refinement summary of 1-4.

\begin{tabular}{|c|c|c|c|c|}
\hline & 1 & 2 & 3 & 4 \\
\hline Empirical Formula & $\mathrm{C}_{22} \mathrm{H}_{18} \mathrm{~N}_{12} \mathrm{O}_{6} \mathrm{Zn}$ & $\mathrm{C}_{22} \mathrm{H}_{18} \mathrm{~N}_{12} \mathrm{O}_{6} \mathrm{Cd}$ & $\mathrm{C}_{22} \mathrm{H}_{22} \mathrm{~N}_{12} \mathrm{O}_{8} \mathrm{Zn}$ & $\mathrm{C}_{22} \mathrm{H}_{22} \mathrm{~N}_{12} \mathrm{O}_{8} \mathrm{Cd}$ \\
\hline Fw & 611.85 & 658.88 & 647.89 & 694.92 \\
\hline Crystal dimensions $\left(\mathrm{mm}^{3}\right)$ & $0.150 \times 0.12 \times 0.08$ & $0.12 \times 0.09 \times 0.07$ & $0.20 \times 0.10 \times 0.12$ & $0.21 \times 0.19 \times 0.10$ \\
\hline Crystal system & Monoclinic & Monoclinic & Monoclinic & Monoclinic \\
\hline Space group & $P 2{ }_{1} / n$ & $P 2{ }_{1} / n$ & $P 2{ }_{1} / c$ & $C 2$ \\
\hline$a, \AA$ & $9.3561(9)$ & $9.3490(18)$ & $8.607(2)$ & $9.3655(9)$ \\
\hline$b, \AA$ & $10.9855(11)$ & $11.162(2)$ & $16.275(4)$ & $16.551(2)$ \\
\hline$c, \AA$ & $11.4548(12)$ & $11.688(2)$ & $9.231(2)$ & $8.6129(8)$ \\
\hline$\beta,\left(^{\circ}\right)$ & $95.176(2)$ & $95.094(3)$ & $92.960(4)$ & $93.664(2)$ \\
\hline$V, \AA^{3}$ & $1172.5(2)$ & $1214.9(4)$ & 1291.3(6) & $1332.4(2)$ \\
\hline$Z$ & 2 & 2 & 2 & 2 \\
\hline$\rho_{\text {calcd }}, \mathrm{mg} / \mathrm{m}^{3}$ & 1.733 & 1.801 & 1.666 & 1.732 \\
\hline$\mu, \mathrm{mm}^{-1}$ & 1.118 & 0.967 & 1.026 & 0.892 \\
\hline$F(000)$ & 624 & 660 & 666 & 700 \\
\hline$T(\mathrm{~K})$ & $100(2)$ & $100(2)$ & $100(2)$ & $100(2)$ \\
\hline$\theta_{\min / \max }$ range $\left(^{\circ}\right)$ & $2.57-28.33$ & $2.53-28.35$ & $2.57-28.33$ & $2.37-25.00$ \\
\hline Range of $h, k, l$ & $\begin{array}{l}-11 / 12,-14 / 11 \\
-15 / 11\end{array}$ & $\begin{array}{l}-12 / 5,-13 / 14 \\
-15 / 14\end{array}$ & $\begin{array}{l}-8 / 11,-21 / 18 \\
-12 / 9\end{array}$ & $\begin{array}{l}-11 / 10,-18 / 19 \\
-7 / 10\end{array}$ \\
\hline Reflections collected/unique & $7513 / 2892$ & $7698 / 2983$ & 8211 & $3445 / 2189$ \\
\hline Data/ restraints /parameter & $2892 / 0 / 187$ & $2983 / 0 / 187$ & $3159 / 3 / 201$ & $2189 / 182 / 200$ \\
\hline GOF on $F^{2}$ & 1.156 & 1.216 & 1.145 & 1.073 \\
\hline$R_{\text {int }}$ & 0.0370 & 0.0308 & 0.0327 & 0.0270 \\
\hline$R 1 ; w R 2[I>2 \sigma(I)]$ & $0.0494 ; 0.0958$ & $0.0396 ; 0.0762$ & $0.0534 ; 0.1291$ & $0.0598 ; 0.1451$ \\
\hline$R 1 ; w R 2$ (all data) & $0.0704 ; 0.1325$ & $0.0610 ; 0.1210$ & $0.0789 ; 0.1901$ & $0.0639 ; 0.1570$ \\
\hline
\end{tabular}




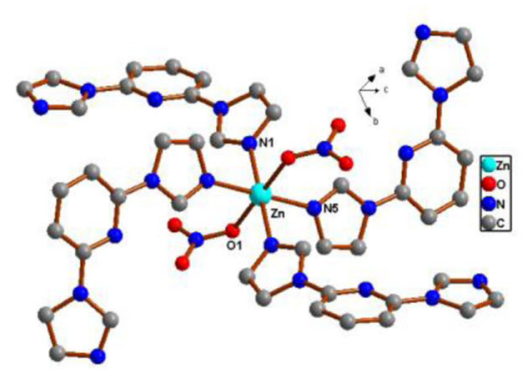

(a)

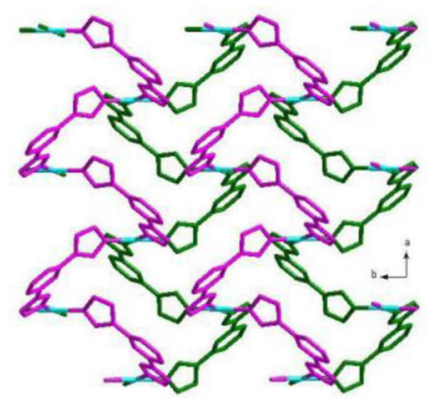

(c)

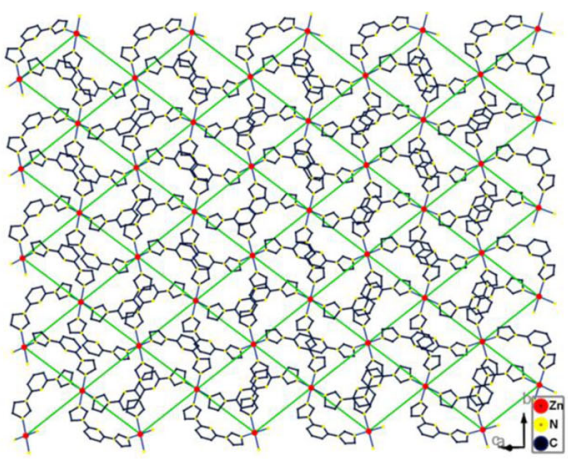

(b)

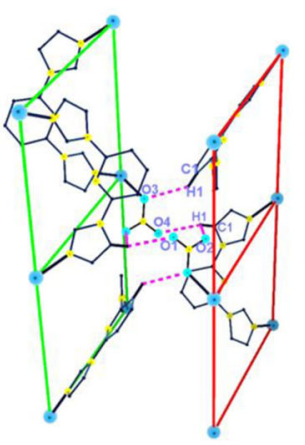

(d)

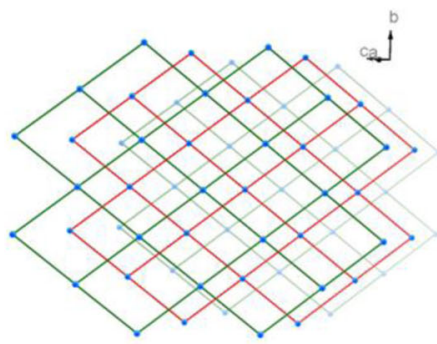

(e)

Figure 1. (a) The coordination environment around $\mathrm{Zn}(\mathrm{II})$ ions in $\mathbf{1}$ (hydrogen atoms omitted for clarity). (b) Stick view of the 2-D helical coordination polymer of $\mathbf{1}$ along a-axis. (c) View of two-dimensional layer comprising left-handed (pink) and right-handed (green) helical chains in 1. (d) C-H. . O interaction between the grids in $\mathbf{1}$ (bond distances $(\AA)$ and angles $\left.\left({ }^{\circ}\right)\right)$ : $\mathrm{O} 1 \cdots \mathrm{H} 5=2.638(3), \mathrm{O} 3 \cdots \mathrm{H} 9=2.600(2), \mathrm{O} 2 \cdots \mathrm{H} 9=2.666(2), \mathrm{C} 5-\mathrm{H} 5 \cdots \mathrm{O} 1=$ 130.02(15), C9-H9 $\cdots \mathrm{O} 3=161.98(15), \mathrm{C} 9-\mathrm{H} 9 \cdots \mathrm{O} 2=108.75(15)$. (e) Stacking of 2-D grid structures in 1 along a-axis. Symmetry codes: (i) $-\mathrm{x}+3 / 2, \mathrm{y}-1 / 2,-\mathrm{z}-1 / 2$; (ii) $\mathrm{x}+1 / 2$, $-\mathrm{y}+1 / 2, \mathrm{z}+1 / 2$; (iii) $-\mathrm{x}+2,-\mathrm{y},-\mathrm{z}$; (iv) $-\mathrm{x}+3 / 2, \mathrm{y}+1 / 2,-\mathrm{z}-1 / 2$. Important bond distances $(\AA)$ and angles $\left(^{\circ}\right)$ for 1: Zn-N1, 2.201(3); Zn-N5, 2.123(3); Zn-O1, 2.201; N1Zn-N1, 180; N5-Zn-N5, 180; O1-Zn-O1, 180; N1-Zn-N5, 87.07(11); N5-Zn-O1, 85.22(11); $\mathrm{N} 1-Z n-O 1,87.70(11)$. Symmetry codes in 2: (i) $\mathrm{x}, \mathrm{y}, \mathrm{z}$; (ii) $-\mathrm{x}+1 / 2, \mathrm{y}+1 / 2,-\mathrm{z}+1 / 2$; (iii) $-\mathrm{x},-\mathrm{y},-\mathrm{z}$; (iv) $\mathrm{x}-1 / 2,-\mathrm{y}-1 / 2, \mathrm{z}-1 / 2$. Important bond distances $(\AA)$ and angles ( ${ }^{\circ}$ for 2: Cd-N1, 2.3103(3); Cd-N5, 2.344(3); Cd-O4, 2.344(4); N1-Cd-N1, 180; N5-Cd-N5, 180; O4-Cd-O 4, 180; N1-Cd-N5, 93.87(14); N1-Cd-O1, 85.67(14); N5-Cd-O1, 83.98(16).

closer to the other reported values in the literature of zinc imidazole system. ${ }^{18}$ Interestingly, two of the oxygen atoms of nitrate ions show moderate to weak hydrogen bonding interactions with the axially coordinated water molecules of octahedral zinc leading to the formation of a 2D helical pattern along crystallographic $c$ axis (table S1). Further, the third oxygen atom of the nitrate ions shows shorter $\mathrm{C}-\mathrm{H}$ interactions of two imidazole rings and a pyridine to form 3D network of this 2D helical coordination polymer (figure $2 \mathrm{~d}$ ).

Unlike in the case of $\mathbf{3}$, the single crystal X-ray diffraction study shows that the complex $\{[$ cis-Cd $\left.\left.\left.(\text { pyim })_{2}\right)_{2}\left(\mathrm{H}_{2} \mathrm{O}\right)_{2}\right] \cdot\left(\mathrm{NO}_{3}\right)_{2}\right\}_{\mathrm{n}}(4)$ crystallize in chiral monoclinic space group $C 2$ (table 1). The structure of 4 consists of octahedral cadmium unit $\mathrm{CdN}_{4} \mathrm{O}_{2}$, where cadmium atom is surrounded by oxygen atoms (O1) from two $\mathrm{H}_{2} \mathrm{O}$ molecules, and four nitrogen atoms (N1 and N5) from different pyim ${ }_{2}$ forming a cis coordination geometry (figure $3 \mathrm{a}$ ). The imidazole nitrogen atoms of pyim $_{2}$ connect adjacent layers of the cadmium centre through an equatorial-axial fashion to form the 2D CPs (figure 3b). Among the two imidazoles, one of the imidazole rings is out of plane $\left(24.367^{\circ}\right)$ with respect to the pyridine rings, which originates the helical structures between the adjacent layers of the 4. Unlike 1-3, these helices are of the same type, right-handed helix $(P)$ along $b$ axis (figure $3 \mathrm{c}$ ). The layers consisting of double helices are further stabilized through $\pi-\pi$ interaction between pyridine rings which are stacked face to face on one another. The centroid to centroid distance is $3.168 \AA$ and the angle between the planes is $0.91^{\circ}$. This $\pi-\pi$ interaction leads to a $3 \mathrm{D}$ 


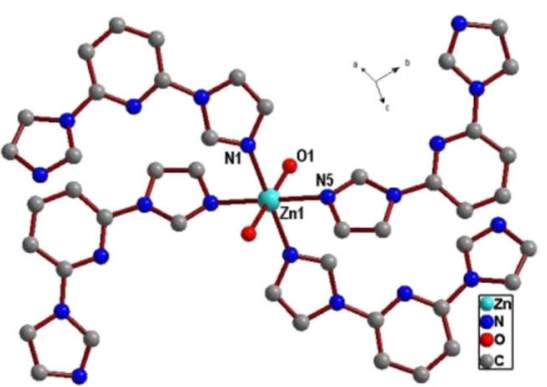

(a)

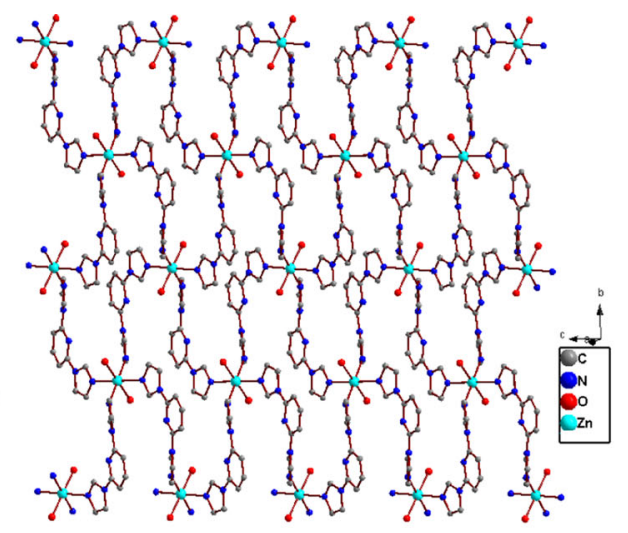

(b)

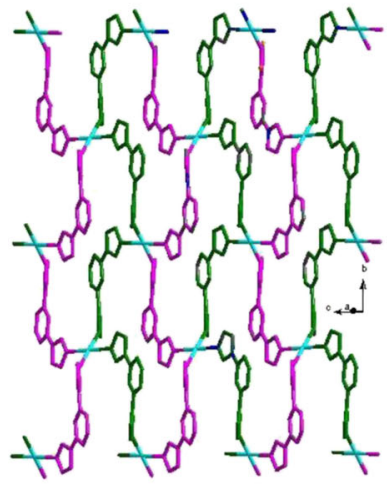

(c)

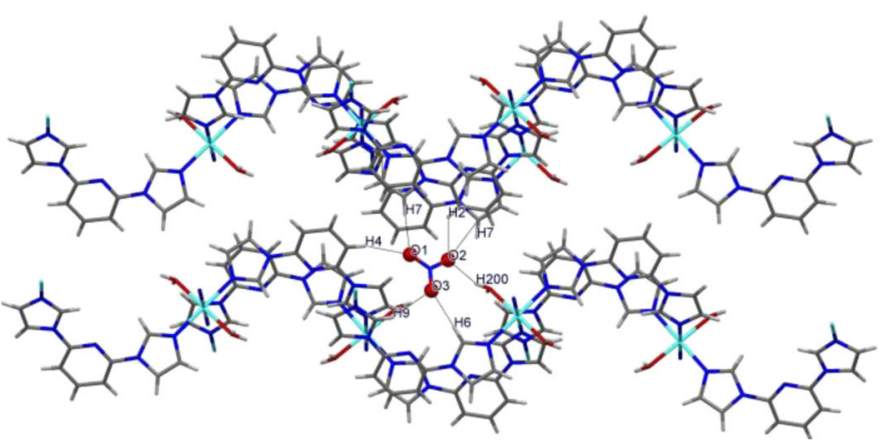

(d)

Figure 2. (a) Coordination environment of $\mathrm{Zn}$ (II) ions in 3 (hydrogen atoms are omitted for clarity). (b) Ball and stick view of metal-ligand 2-D coordination polymer. (c) View of two-dimensional layer comprising left-handed (pink) and right-handed (green) helical chains in 3. (d) 3-D supramolecular structure showing H-bonding by nitrate ions (along $c$-axis). Symmetry codes: (i) $-\mathrm{x}+1,-\mathrm{y},-\mathrm{z}+1$; (ii) $\mathrm{x},-\mathrm{y}+1 / 2, \mathrm{z}-1 / 2$; (iii) $\mathrm{x},-\mathrm{y}+1 / 2, \mathrm{z}+1 / 2$. Important bond distances $(\AA)$ and angles $\left(^{\circ}\right)$ : Zn-N1, 2.139(3); Zn-N5, 2.152(3); Zn-O1, 2.140(3); N1-Zn-N1, 180.0; N5-Zn-N5, 179.99(1); O1-Zn-O1, 180.0; N1-Zn-N5, 85.62(13); N5-Zn-O1, 91.04(12); N1-Zn-O1, 89.72(12).

supramolecular arrangement of this 2D coordination polymer (figure $3 \mathrm{~d}-\mathrm{e}$ ).

The stereoisomeric changes in the coordination geometry from CPs 1-3 coupled with the $\mathrm{C}-\mathrm{N}$ bond rotation greatly influences the structural changes observed in this $2 \mathrm{D}$ coordination polymer, 4 . Thus, the chirality $(\Delta)$ is observed due to the combined effect of cisorientation of the pyim 2 and water molecules around the cadmium centre as well as the non-planarity between imidazole and pyridine rings due to the twist in $\mathrm{C}-\mathrm{N}$ bond between pyridine and imidazoles of the ligand.

The homochirality of $\mathbf{4}$ in bulk was confirmed by taking crystals of different reaction batches for single crystal X-ray diffraction measurements. In all these cases, the structural solution led to the single-handed helicity with the same chirality of $\mathbf{4}$, having the least
Flack parameter value [0.001(1)]. Further, the bulk samples of two to three different batches were taken for the solid state $\mathrm{CD}$ spectrum and solution state polarimetry studies as well as PXRD (figure S2).

\subsection{CD spectra}

The solid state CD spectrum of coordination polymer 4 was recorded between $190-500 \mathrm{~nm}$ at $20^{\circ} \mathrm{C}$. The $\mathrm{CD}$ spectrum showed very small negative Cotton effects between 190-350 $\mathrm{nm}$ range indicating the existence of homochirality of the coordination polymer, 4 (figure S3).

\subsection{Polarimetry}

However, the solution state polarimetric measurements recorded in DMSO solvent showed rotation of the plane 


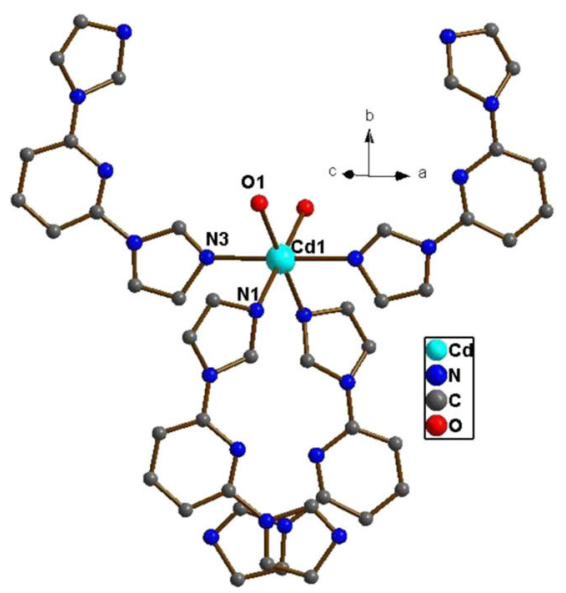

(a)

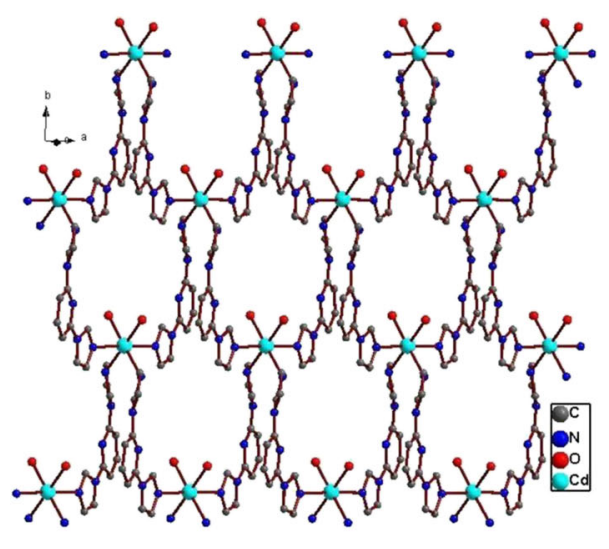

(b)

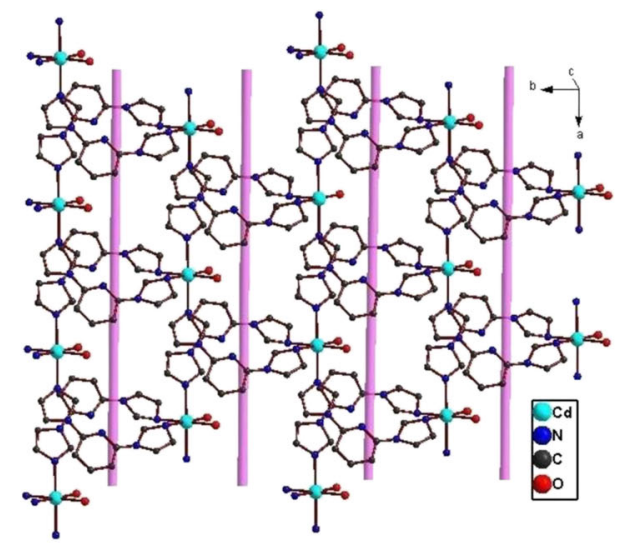

(c)

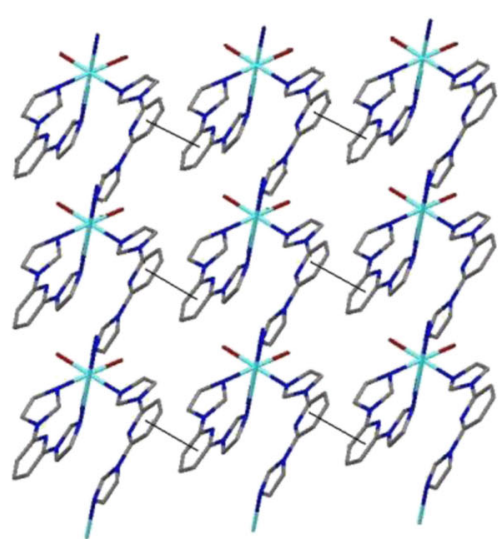

(d)

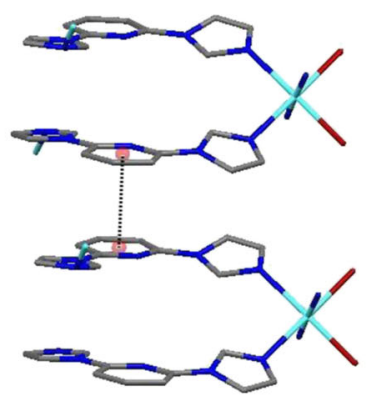

(e)

Figure 3. (a) Coordination environment of $\mathrm{Cd}(\mathrm{II})$ ions in $\mathbf{4}$ (hydrogen atoms are omitted for clarity). (b) Ball and stick view of metal-ligand 2-D coordination polymer. (c) Two right-handed helices running across each other. (d) and (e) $\pi-\pi$ interaction between adjacent layers to form a 3-D supramolecular structure (along a-axis). Symmetry codes: (i) $-\mathrm{x}+1, \mathrm{y},-\mathrm{z}+2$; (ii) $\mathrm{x}-1 / 2, \mathrm{y}-1 / 2$, $\mathrm{z}$; (iii) $\mathrm{x}+1 / 2, \mathrm{y}+1 / 2$, $\mathrm{z}$. Important bond distances $(\AA)$ and angles $\left(^{\circ}\right)$ Cd-N1, 2.297(11); Cd-N3, 2.329(6); Cd-O1, 2.297(10); N1-Cd-N1, 91.7(5); N3-Cd-N3, 178.5(8); O1-Cd-O1, 92.7(5); N1-Cd-N3, 86.9(4); O1-Cd-N3, 92.3(5); O1-Cd-N1, 179.0(6). 
of polarized light to right, and the specific rotation, $[\alpha]_{\lambda}^{T}$ was found to be +1.65 confirming the homochirality of the product. However, it is to be mentioned that after an hour, the loss of chirality of $\mathbf{4}$ was observed in the same solution.

\subsection{Thermogravimetric analysis}

The thermal stability of $\mathbf{1 - 4}$, was studied using the thermogravimetric analysis (TGA) (figure S4). The TGA profiles indicated that $\mathbf{1}$ is thermally stable up to $240^{\circ} \mathrm{C}$ without any loss of weight. Around $240-400^{\circ} \mathrm{C}$ the framework showed $46.0 \%$ weight loss corresponding to the loss of one ligand and one nitrate molecule (calculated, $44.63 \mathrm{wt} \%$ ). The second weight loss of $39.3 \%$ around $400-680^{\circ} \mathrm{C}$ corresponded to the loss of another ligand and another nitrate molecule (calculated, $44.63 \mathrm{wt} \%$ ) (residue 14.1\%). The TGA profile indicated that $\mathbf{2}$ is thermally stable up to $311^{\circ} \mathrm{C}$ without any loss of weight. Around $311-372^{\circ} \mathrm{C}$ the framework showed $39.1 \%$ weight loss corresponding to the loss of one ligand and one nitrate molecule (calculated, $41.44 \mathrm{wt} \%$ ). The $\mathrm{CP}$ shows a gradual weight loss around $380^{\circ} \mathrm{C}$ corresponding to the loss of another ligand and another nitrate molecule (residue $13.1 \%$ ). The TGA profile of $\mathbf{3}$ indicated that it was thermally stable up to $150^{\circ} \mathrm{C}$ and showed first weight loss of around 6\% due to two water molecules at $150-190^{\circ} \mathrm{C}$ (calculated, $5.55 \mathrm{wt} \%$ ). The second weight loss of $47.6 \%$ was observed at around $250-390^{\circ} \mathrm{C}$ due to the loss of two nitrate ions and one ligand (calculated, $51.72 \mathrm{wt} \%$ ). The third weight loss of $30 \%$ was observed at $530-700^{\circ} \mathrm{C}$ for another ligand (calculated, 32.58 wt \%) (residue 22.0\%). The TGA profile of $\mathbf{4}$ indicated that it was thermally stable upto $140^{\circ} \mathrm{C}$ without any weight loss. At around $140-190^{\circ} \mathrm{C}$ it showed weight loss of $6.0 \%$ due to loss of two water molecules (calculated, $5.18 \mathrm{wt} \%$ ). Then the next weight loss of $43.0 \%$ was observed around $250-400^{\circ} \mathrm{C}$ corresponding to two nitrate ions and one ligand (calculated, $48.22 \mathrm{wt} \%$ ). The third weight loss of $28.0 \%$ was at around $550-740^{\circ} \mathrm{C}$ due to another ligand molecule (calculated, $30.37 \mathrm{wt} \%$ ) (residue 26.1\%).

\section{Conclusion}

Four new CPs (1-4) were synthesized using achiral angular ditopic ligand $\left(\right.$ pyim $\left._{2}\right)$ and structurally characterized, in which lone pair on pyridine nitrogen were not involved in coordination with metal centres. The latter can be used as a source of Lewis base assisted organic reaction or transformation. These CPs showed different metal coordination environment and structures with change of solvent conditions. The result was the formation of a homochiral coordination polymer $\mathbf{4}$ by spontaneous resolution. The homochirality in bulk of the product 4 was further supported by recording the optical activity using polarimetry and in solid state CD spectra. In fact, to the best of our knowledge, this is the first time that the solution state polarimetric measurements were carried out for the CPs. Further, studies on the preparation of chiral CPs using different metal salts using pyim $_{2}$ and other co-ligands under soft route and their use as chiral platform for the separation and catalysis are under progress.

\section{Supplementary Information}

CCDC-972289-972292 contains the supplementary crystallographic data for this paper. These data can be obtained free of charge from The Cambridge Crystallographic Data Centre via www.ccdc.cam.ac.uk/data request/cif. Selected bond lengths and angles, additional figures, TGA and powder X-ray diffraction patterns. For supplimentary Information, see www.ias.ac. in/chemsci.

\section{Acknowledgements}

The authors thank Council of Scientific and Industrial Research (CSIR), Department of Science and technology (DST), Government of India for financial support and Indian Institute of Technology (IIT), Kanpur for infrastructural facilities. Also we thank "Thematic Unit of Excellence on Soft Nanofabrication with Application in Energy, Environment and Bioplatform at IIT Kanpur" for PXRD facility. ST (CSIR), RS (IITK), and NS (University of Grant Commission, UGC) thank the respective agencies mentioned in the brackets for research fellowships. We are thankful to Dr. Mrinalini G. Walawalkar and M. Nethaji for crystallographic support on complex 4.

\section{References}

1. (a) Furukawa H, Cordova K E, O'Keeffe M and Yaghi O M 2013 Science 341; (b) Sumida K, Rogow D L, Mason J A, McDonald T M, Bloch E D, Herm Z R, Bae T H, and Long J R 2012 Chem. Rev. 112 724; (c) Wu H, Gong Q, Olson D H and Li J 2012 Chem. Rev. 112 836; (d) Getman R B, Bae Y S, Wilmer C E and Snurr R Q 2012 Chem. Rev. 112 703; (e) Suh M P, Park H J, Prasad T K and Lim D W 2012 Chem. Rev. 112 782; (f) Li J R, Ma Y, McCarthy M C, Sculleya J, Yub J, Jeong H K, Balbuena P B and Zhou H C 2011 Coord. Chem. Rev. 255 1791; (g) Han S S, Mendoza-Cortés J L and Goddard III W A 2009 Chem. Soc. Rev. 38 1460; (h) Czaja A U, Trukhan N and Müller U 2009 Chem. Soc. Rev. 38 1284; (i) Murray L J, Dincă M and Long 
J R 2009 Chem. Soc. Rev. 38 1294; (j) Kitagawa S, and Matsuda R. 2007 Coord. Chem. Rev. 251 2490; (k) Kitagawa S and Uemura K 2005 Chem. Soc. Rev. 34109

2. Li J R, Sculley J and Zhou H C 2012 Chem. Rev. 112 869

3. (a) Landee C P and Turnbull M M 2013 Eur. J. Inorg. Chem. 2266; (b) Zhang W and Xiong R G 2012 Chem. Rev. 112 1163; (c) Rogez G, Viart N and Drillon M 2010 Angew. Chem. Int. Ed. 49 1921; (d) Kurmoo M 2009 Chem. Soc. Rev. 38 1353; (e) Train C, Gheorghe R, Krstic V, Chamoreau L M, Ovanesyan N S, Rikken G L J A, Gruselle M and Verdaguer M 2008 Nat. Mater. 7 729; (f) Bogani L, Cavigli L, Bernot K, Sessoli R, Gurioli M and Gatteschi D 2006 J. Mater. Chem. 16 2587; (g) Coronado E, Galán-Mascarós J R, GómezGarcía C J and Martínez-Agudo J M 2001 Inorg. Chem. 40113

4. (a) Yoon M, Srirambalaji R and Kim K 2012 Chem Rev. 112 1196; (b) Corma A, García H and Llabrés i Xamena F X 2010 Chem. Rev. 110 4606; (c) Yu L, Wang Z, Wu J, Tu S and Ding K 2010 Angew. Chem. Int. Ed. 49 3627; (d) Liu Y, Xuan W and Cui Y 2010 Adv. Mater. 22 4112; (e) Ma L, Abney C and Lin W 2009 Chem. Soc. Rev. 38 1248; (f) Lee J Y, Farha O K, Roberts J, Scheidt K A, Nguyen S T and Hupp J T 2009 Chem. Soc. Rev. 38 1450; (g) Jammi S, Rout L, Saha P, Akkilagunta V K, Sanyasi S and Punniyamurthy T 2008 Inorg. Chem. 47 5093; (h) Ding K, Wang Z and Shi L 2007 Pure Appl. Chem. 79 1531; (i) Ding K, Wang Z, Wang X, Liang Y and Wang, X. Chem. Eur. J. 2006, 125188

5. (a) Cui Y, Yue Y, Qian G and Chen B 2012 Chem. Rev. 112 1126; (b) Wang C, Zhang T and Lin W 2012 Chem. Rev. 112 1084; (c) Allendorf M D, Bauer C A, Bhakta R K and Houka R J T 2009 Chem. Soc. Rev. 38 1330; (d) Liu Y, Li G, Li X and Cui Y 2007 Angew. Chem. Int. Ed. 46 6301; (e) Janiak C 2003 Dalton Trans. 2781; (f) Evans O R and Lin W 2002 Acc. Chem. Res. 35511

6. (a) Zheng X D and Lu T B 2010 CrystEngComm. 12 324; (b) Han L and Hong M 2005 Inorg. Chem. Commun. 8 406; (c) Albrecht M 2001 Chem. Rev. 101 3457; (d) Piguet C, Bernardinelli G and Hopfgartner G 1997 Chem. Rev. 972005

7. Lehn J M 1995 In Supramolecular Chemistry (Germany:VCH, Weinheim)

8. (a) Crassous J 2009 Chem. Soc. Rev. 38 830; (b) Morris R E and Bu X 2010 Nature Chem. 2 353; (c) Lin W 2005 J. Solid State Chem. 1782486

9. (a) He W W, Yang J, Yang Y, Liu Y Y and Ma J F 2012 Dalton Trans. 41 9737; (b) Dong D P, Sun Z G, Tong F, Zhu Y Y, Chen K, Jiao C Q, Wang C L, Li C and Wang W N 2011 CrystEngComm 13 3317; (c) Ryoo J J, Shin J W, Dho H S and Min K S 2010 Inorg. Chem. 497232 ; (d) Wang Y, Fu H, Shen F, Sheng X, Peng A, Gu Z, Ma H, Ma J S and Yao J 2007 Inorg. Chem. 46 3548; (e) Wu C D, Ngo H L and Lin W 2004 Chem. Commun. 1588; (f) Cui Y, Ngo H L and Lin W 2003 Chem. Commun. 1388; (g) Cui Y, Ngo H L, White P S and Lin W 2002 Chem. Commun. 1666; (h) Bernhard S, Takada K, Díaz D J, Abruña H D and Mürner H $2001 \mathrm{~J}$. Am. Chem. Soc. 12310265

10. Amghouz, Z, Roces L, García-Granda S and García J R 2010 Inorg. Chem. 497917
11. Kang Y, Chen S, Wang F, Zhang J and Bu X 2011 Chem. Commun. 474950

12. (a) Cai S L, Zheng S R, Wen Z Z, Fan J and Zhang W G 2012 Cryst. Growth Des. 12 2355; (b) Zuo Y, Fang M, Xiong G, Shi P F, Zhao B, Cui J Z and Cheng P 2012 Cryst. Growth Des. 12 3917; (c) Chang C C, Huang Y C, Huang S M, Wu J Y, Liu Y H and Lu K L 2012 Cryst. Growth Des. 12 3825; (d) Yi F Y, Zhang J, Zhang H X, Sun Z M 2012 Chem. Commun. 48 10419; (e) Zhang H X, Wang F, Tan Y X, Kang Y and Zhang J 2012 J. Mater. Chem. 22 16288; (f) Tan X, Zhan J, Zhang J, Jiang L, Pan M and Su C Y 2012 CrystEngComm 14 63; (g) Zheng S R, Cai S L, Tan J B, Fan J and Zhang W G 2012 CrystEngComm 14 6241; (h) Bisht K K and Suresh E 2012 Inorg. Chem. 519577

13. (a) Croitor L, Coropceanu E B, Siminel A V, Kravtsov V C and Fonari M 2011 Cryst. Growth Des. 11 3536; (b) Chen S C, Zhang J, Yu R M, Wu X Y, Xie Y M, Wang F and Lu C Z 2010 Chem. Commun. 46 1449; (c) Liu W T, Ou Y C, Lin Z J and Tong M L 2010 Cryst. Eng. Comm. 12 3487; (d) Han Z B, Ji J W, An H Y, Zhang W, Han G X, Zhang G X and Yang L G 2009 Dalton Trans. 9807; (e) Lennartson A and Håkansson M 2009 Angew. Chem. Int. Ed. 48 5869; (f) Zhang J, Chen S, Wu T, Feng $\mathrm{P}$ and $\mathrm{Bu} X 2008 \mathrm{~J}$. Am. Chem. Soc. 130 12882; (g) Lu W G, Gu J Z, Jiang L, Tan M Y and Lu T B 2008 Cryst. Growth Des. 8 192; (h) Feller R K and Cheetham A K 2008 Dalton Trans. 2034; (i) Hou S Z, Cao D K, Li Y Z and Zheng L M 2008 Inorg. Chem. 47 10211; (j) Zou R Q, Zhong R Q, Du M, Pandey D S and Xu Q 2008 Cryst. Growth. Des. 8452

14. (a) Zhang Q, Bu X, Lin Z, Biasini M, Beyermann W P and Feng P 2007 Inorg. Chem. 46 1419; (b) Li F, Li T, Li X, Li X, Wang Y and Cao R 2006 Cryst. Growth Des. 6 1458; (c) Gu X and Xue D 2006 Inorg. Chem. 45 9257; (d) Tian G, Zhu G, Yang X Fang Q, Xue M, Sun J, Wei Y and Qiu S 2005 Chem. Commun. 1396; (e) Balamurugan V and Mukherjee R 2005 Cryst. Eng. Comm. 7 337;(f) Wang Y T, Tong M L, Fan H H, Wang H Z and Chen X M 2005 Dalton Trans. 424; (g) Gao E Q, Yue Y F, Bai S Q, He Z and Yan C H 2004 J. Am. Chem. Soc. 1261419

15. Ezuhara T, Endo K and Aoyama Y 1999 J. Am. Chem. Soc. 1213279

16. Miessler G L and Tarr D A 2009 In Inorganic Chemistry. $3^{\text {rd }}$ Ed., Dorling Kindersley Ind. Pvt. Ltd

17. (a) Chen C Y, Cheng P Y, Wu H H and Lee H M 2007 Inorg. Chem. 46 5691; (b) Caballero A, Díez-Barra E, Jalón F A, Merino S and Tejeda J 2001 J. Organomet. Chem. $\mathbf{6 1 7} 395$

18. Zhang S, Lan J, Mao Z, Xie R. and You J 2008 Cryst. Growth Des. 83134

19. (a) Chun-Long Chen C L, Goforth A M, Smith M D, Cheng-Yong Su C Y and Zur Loye H C 2005 Inorg. Chem. 44 8762; (b) Masciocchi N, Pettinari C, Alberti E, Pettinari R, Nicola C D, Albisetti A F and Sironi A 2007 Inorg. Chem. 4610501

20. Sheldrick G M 1997 SHELXL-97: Program for Crystal Structure Refinement: University of Göttingen, Göttingen, Germany

21. Sheldrick G M 1998 SHELXTL Reference Manual: Version 5.1, Bruker AXS, Madison, WI

22. G M Sheldrick 2000 SADABS 2.0 